\title{
A case of 25 gauge vitrectomy for malignant glaucoma with microphthalmos
}

This article was published in the following Dove Press journal:

Clinical Ophthalmology

30 May 2013

Number of times this article has been viewed

\section{Masami Nakajima \\ Yusuke Hara \\ Yoshio Yamazaki}

Department of Ophthalmology, Division of Visual Science, Nihon University School of Medicine,

Tokyo, Japan
Correspondence: Masami Nakajima

Department of Ophthalmology,

Division of Visual Science, Nihon

University School of Medicine, 30-I,

Oyaguchi-kamimachi, Itabashi,

Tokyo 173-86I0, Japan

Tel +8I 339728 III

Fax +8I 359953495

Email nakajima.masami@nihon-u.ac.jp
Abstract: We report the first case report of pars plana lensectomy (PPL) and pars plana vitrectomy using a 25 gauge vitrectomy system for microphthalmos.

Results: A 45-year-old woman reported repeated pain in her left eye, despite the use of medications. Ultrasound biomicroscopy revealed a narrow angle and thickened sclera. The lens and the iris showed anterior displacement with a flattening of the ciliary body. The axial length was $15.16 \mathrm{~mm}$ in the right eye and $15.04 \mathrm{~mm}$ in the left eye. She was diagnosed with a malignant glaucoma with microphthalmos. The patient underwent PPL and pars plana vitrectomy, using a 25 gauge vitrectomy system. The intraocular pressure was well controlled after surgery without medication.

Conclusion: We considered the PPL and 25 gauge vitrectomy effective in microphthalmos when performed safely.

Keywords: microphthalmos, aqueous misdirection, malignant glaucoma, ultrasound biomicroscopy, 25 gauge vitrectomy

\section{Introduction}

Microphthalmos is accompanied by insufficient aqueous outflow and compression of vortex veins due to abnormal thickness of sclera. ${ }^{1}$ Relative increase in lens volume causes a ciliary block, inducing malignant glaucoma in microphthalmos. In these conditions, careful management is needed to avoid severe complications, such as uveal effusion and expulsive hemorrhage. ${ }^{2}$ So far as we know, this is the first case report of malignant glaucoma with microphthalmos undergoing vitrectomy using a 25 gauge system without severe complication.

\section{Case report}

A 45-year-old woman complained of blurred vision in her left eye. She had a past history of peripheral laser iridotomy performed in both eyes by a local ophthalmologist 11 months previously. The diagnosis was an acute onset of angle closure glaucoma. She was treated with pilocarpine (4 times/day), and oral acetazolamide (1000 mg/day). She was referred to Nihon University Itabashi hospital in January 2009. Although she occasionally had blurred vision in her left eye, the intraocular pressure (IOP) was controlled by topical and systemic medications. She complained of repeated eye pain during the night from April 2009.

Her visual acuity was $0.05(0.4 \times+15.0$ Diopter (D), Cylinder (cyl), +1.50 D, Axis (Ax) $\left.80^{\circ}\right)$ in the right eye and $0.07\left(0.4 \times+13.0 \mathrm{D}\right.$, cyl $\left.+1.75 \mathrm{D}, \mathrm{Ax} 90^{\circ}\right)$ in the left eye. The IOPs were $8 \mathrm{mmHg}$ in the right and $12 \mathrm{mmHg}$ in the left (with medication). 
The corneal diameter was $11 \mathrm{~mm}$ without corneal opacity. Despite an extremely narrow anterior chamber, there was no lens-corneal touch (Figure 1A). A slight nuclear cataract, along with slight extension of the retinal veins were observed. Ultrasound biomicroscopy (UBM) revealed a narrow angle and thickened sclera. The lens and the iris showed anterior displacement with a flattening of the ciliary body (Figure 1B). The axial length was $15.16 \mathrm{~mm}$ in the right eye and $15.04 \mathrm{~mm}$ in the left eye.

We performed a pars plana lensectomy (PPL), a pars plana vitrectomy (PPV) and an intra ocular lens (IOL) implantation on her left eye in August 2009. Surgery was performed with a three port PPV using a 25 gauge vitrectomy system (Accurus 800CS, Alcon Surgical, Fort Worth, TX, USA). Cares were taken in respect to anatomical abnormality in microphthalmos, and three trocars were inserted at the site $1 \mathrm{~mm}$ or $1.5 \mathrm{~mm}$ from the limbus. PPL was performed to relieve the lens-vitreous adhesions using a cutter. After injection of triamcinolone acetonide (Kenacort ${ }^{\circledR}$, Bristol-Myers Squibb Co, Princeton, NJ, USA) in the vitreous cavity, PPV was performed to relieve cilio-vitreous adhesions, and vitreous remnant using the vitrectomy instrument in conjunction with scleral depression (Figure 2). The anterior chamber began to deepen intraoperatively. At the end of surgery, on the bug IOL implantation was performed. There was no major intraoperative complication. Three months' after surgery, the patient's left visual acuity was $0.3\left(0.4 \times+14.0 \mathrm{D}, \mathrm{cyl}+1.25 \mathrm{D}, \mathrm{Ax} 120^{\circ}\right)$. Slit lamp biomicroscopy examination and UBM revealed a deep anterior chamber (Figure 1C and D). One year after surgery, the IOP was well controlled without medication.

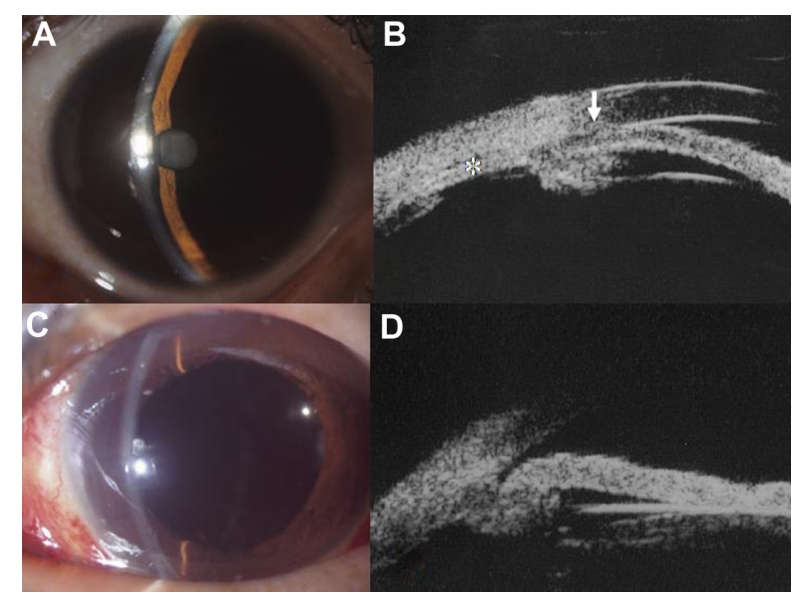

Figure I Anterior segment photograph and ultrasound biomicroscopy (UBM) of the left eye. Before surgery: (A) slit lamp biomicroscopy examination shows an extremely narrow anterior chamber. (B) UBM shows the narrow angle (arrow), the flat ciliary body (asterisk) and thickened sclera. The lens and iris move to the anterior. After surgery: (C and $\mathbf{D}$ ) slit lamp biomicroscopy examination and UBM show a deep anterior chamber.

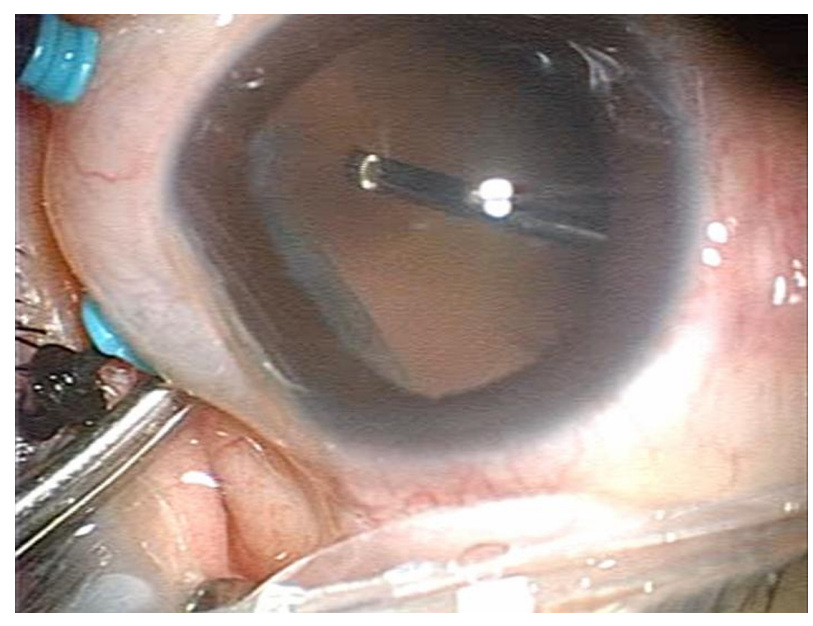

Figure 2 Pars plana vitrectomy using a 25 gauge system.

Note: Vitrectomy was performed using the scleral depression technique to remove the ciliary block.

\section{Discussion}

Duke-Elder defined the microphthalmos as being an eye of small size, about two-thirds below that of a normal eye, without other malformations. ${ }^{3}$ Clinical features that frequently accompanied microphthalmos are hypermetropia, macular hypoplasia, and glaucoma. Majima defined microphthalmos in adults as a short axial length below $20.4 \mathrm{~mm}$ in males, and $20.1 \mathrm{~mm}$ in females. ${ }^{4}$ Our case fits the definition of microphthalmos. The pathogenesis of malignant glaucoma is thought to result from aqueous outflow misdirection toward the posterior segment to the vitreous body, causing a ciliolenticular or ciliovitreous block. ${ }^{5}$ Subsequently, iris and lens move anteriorly, resulting in an extreme shallow anterior chamber and raised IOP. UBM revealed the anterior shift of the iris and the lens, and the flattening of the ciliary body. These findings suggest an aqueous misdirection toward the vitreous cavity. Despite laser iridotomy, the anterior chamber was extremely shallow and some pain in the eye was repeatedly reported. These clinical courses indicate the persistence of a chronic ciliary block. In such cases vitrectomy is a useful therapeutic method, but the large wound is at high risk of uveal effusion, and expulsive hemorrhage. Therefore we performed a PPL and an anterior vitrectomy using a 25 gauge system as surgical treatment. Careful vitrectomy is important to remove the vitreous remnant adjacent to the ciliary body using the technique of scleral depression. In such instance, PPL is more effective in relieving the ciliary block, as compared to phacoemulsification. Furthermore, we were able to cut the vitreous remnant with greater safety after identifying this structure, using an injection of triamcinolone acetonide. The anterior chamber was deepened and the ciliary block was relieved 
during vitrectomy. After vitrectomy, a foldable IOL was easily and safely implanted on the anterior capsular bag.

Vitrectomy with the 25 gauge system enabled us to perform a small incision procedure, and minimally invasive surgery for the conjunctiva. Preservation of the conjunctiva is important for the glaucoma eye. Although postoperative ocular hypotony is a possibility, trocar insertion with a beveled scleral tunnel can prevent intraocular fluid leakage in the post operative period. A serious ocular hypotony did not occur in this case. Care must be taken not to injure the opposite retina in the short axial eye, such as microphthalmos, when a trocar is inserted. When comparing retinopathy of prematurity, there is no proliferative membrane and traction retinal detachment in microphthalmos. Furthermore, it is well known in microphthalmos that pars plana length is very short. Therefore, we should exercise great caution when making a scleral port. We considered the PPL and 25 gauge vitrectomy were effective in microphthalmos when performed safely.

\section{Acknowledgments}

The authors thank Professor Mitsuru Sawa for useful advice and editing of this manuscript. Informed consent was obtained for the indicated surgery.

\section{Disclosure}

The authors have no conflicts of interest to report in this work.

\section{References}

1. Brockhurst RJ. Nanophthalmos with uveal effusion: a new clinical entity. Arch Ophthalmol. 1975;93:1289-1299.

2. Yalvac IS, Satana B, Ozkan G, Eksioglu U, et al. Management of glaucoma in patients with nanophthalmos. Eye. 2008;22:838-843.

3. Duke-Elder S. Anomalies in the size of the eye. In: Duke-Elder S, Editor. System of Ophthalmology. Vol III, part 2. St. Louis, MO: Mosby-Year Book; 1963;p. 488-495.

4. Majima A. Microphthalmos and its pathogenic classification. $J$ Jpn Ophthalmol Soc. 1994;98:1180-1200.

5. Jarnour JW, Rubsamen PE, Palmberg P. Pars plana vitrectomy in the management of phakic and pseudophakic malignant glaucoma. Arch Ophthalmol. 1996;114:1073-1078.
Clinical Ophthalmology

\section{Publish your work in this journal}

Clinical Ophthalmology is an international, peer-reviewed journal covering all subspecialties within ophthalmology. Key topics include: Optometry; Visual science; Pharmacology and drug therapy in eye diseases; Basic Sciences; Primary and Secondary eye care; Patien Safety and Quality of Care Improvements. This journal is indexed on

Submit your manuscript here: http://www.dovepress.com/clinical-ophthalmology-journal

\section{Dovepress}

PubMed Central and CAS, and is the official journal of The Society of Clinical Ophthalmology (SCO). The manuscript management system is completely online and includes a very quick and fair peer-review system, which is all easy to use. Visit http://www.dovepress.com/ testimonials.php to read real quotes from published authors. 